\title{
Collaborative case-based learning process in research ethics
}

\author{
Anu Tammeleht ${ }^{1,2^{*}}$ D, María Jesús Rodríguez-Triana ${ }^{2}$, Kairi Koort ${ }^{2}$ and Erika Löfström ${ }^{1}$
}

\author{
* Correspondence: anu.tammeleht@ \\ helsinki.fi \\ ${ }^{1}$ University of Helsinki, \\ Yliopistonkatu 4, 00100 Helsinki, \\ Finland \\ ${ }^{2}$ Tallinn University, Narva mnt 25, \\ 10120 Tallinn, Estonia
}

\begin{abstract}
The increasing concern about ethics and integrity in research communities has brought attention to how students and junior academics can be trained on this regard. Moreover, it is known that ethical behaviour and integrity not only involve individual but also group norms and considerations. Thus, through action research and participant observation, this research investigates the learning processes through which 64 students collaboratively develop research ethics and integrity competencies. The aim was to understand how bachelor, master and PhD students approach ethical dilemma cases through a collaborative process. The data consisted of recorded group work on ethics cases, student group reports, and post-training questionnaires. Later, the analyses considered groups as the unit of analysis. These data were analysed through content analysis utilizing the SOLO taxonomy to identify levels of understanding and assess evolvement of ethical sensitivity during a casebased training session. The results show that all groups reached the level of understanding where the groups demonstrated that concepts had been understood appropriately, but occasionally struggled to make connections between them. Students perceived working collaboratively as beneficial. The results help teachers of research ethics and integrity to make pedagogically justified choices in their teaching. Drawing on the results of this study, we propose a tool for the formative assessment of student learning of research ethics and integrity.
\end{abstract}

Keywords: Ethics, Integrity, Ethics competencies, Case-based learning, Collaboration, Learning process

\section{Introduction}

Academic ethics is part of the competences ('general abilities', as specified in Suciu and Mâță 2010) that graduates of Higher Education should have. Ethical issues are central in the research process and it is in the interest of the entire research community to assure that its members adhere to high standards of ethics and integrity (e.g. Anderson et al. 2013). With the revision of the European Code of Conduct (ALLEA 2017) and simultaneous work to create or update national codes in many EU member states (e.g. Estonian Code of Conduct for Research Integrity was revised in 2017) research ethics and integrity have been high on the agenda of the European research community. There is both need and momentum for implementing the guidelines and developing research ethics and integrity competencies ('specific set of skills, knowledge, abilities' as specified in Suciu and Mâță 2010) among students and academics, the current research focusing on students of various degree levels.

(c) The Author(s). 2019 Open Access This article is distributed under the terms of the Creative Commons Attribution 4.0 International License (http://creativecommons.org/licenses/by/4.0/), which permits unrestricted use, distribution, and reproduction in any medium, provided you give appropriate credit to the original author(s) and the source, provide a link to the Creative Commons license, and indicate if changes were made. 
The term academic ethics includes being honest and achieving fidelity in teaching, learning and research in the research community (Turner and Beemsterboer 2003; Löfström et al. 2015). We include the terms of both research ethics and integrity in our article, and treat academic ethics as a general concept for moral and ethical considerations in an academic context.

Academics and administrators of higher education institutions generally agree that ethical research is an institutional priority, but their views diverge on how students obtain such knowledge, skills and values, whose task it is to teach students, and what can be taught in the first place (Löfström et al. 2015; Shephard et al. 2015). There is a variety of opinions on how ethics and integrity could be taught and who should do it; whether to implicitly model desired behaviours or to teach it explicitly, and whether or not it is academics role to teach ethics or not. There are also academics who think integrity cannot be taught as students either have a moral compass or they do not have it (Löfström et al. 2015; Hyytinen and Löfström 2017).

Many of the strategies used by academics may be intuitive in the sense that they are based on belief, opinion or experience, but rarely research. There are also various pedagogical strategies that have proven to be effective in teaching transversal skills, including ethics and integrity, for example, cases have been proven to be efficient in ethics education (Zucchero 2008; Fisher and Kuther 1997; Rissanen and Löfström 2014). In addition, collaboration and teamwork enhance student learning and understanding especially in learning tasks that are complex and involve the need for multiple perspectives, such as in problem-based and inquiry learning (Johnson and Johnson 1986, 1999; Slavin 1980). In addition, taking into account that in real practice, ethical behaviour and integrity entail interacting with peers and other individuals, training these competencies through collaborative activities could be especially suitable.

While prior studies (e.g. Zucchero 2008; Fisher and Kuther 1997) provide assurance that cases, on the one hand, and group work (e.g. Smith et al. 2005), on the other hand, are effective teaching and learning activities, there is not much knowledge about what takes place during the learning process in settings that combine both ethics cases and group collaborative work. Therefore, the aim of this study was to analyse the anatomy of the learning process when bringing these two commonly applied teaching methods together. The article reports the results of analysing the learning process of a total of 64 bachelor, master and $\mathrm{PhD}$ students in the context of 6 research ethics workshops at an Estonian university. As a practical application based on the research, we offer an assessment tool for teachers of ethics to evaluate students' progress in collaborative case-based ethics teaching.

\section{Ethical sensitivity and pedagogy for developing ethical competence}

The concept ethical sensitivity describes a cognitive competence where the person first becomes aware of the presence of an ethical issue, is then able to recognise the involved parties of the case, and finally consider various courses of action and their implications (Rest 1986; Myyry 2003; Morton et al. 2006). In this concept we include first tuning in to the possibility of ethical concerns in a given situation, and then gradually developing the sensitivity by considering different stakeholders and different courses of action and their implications. In addition, there is content- 
related knowledge and knowledge pertaining to guidelines and procedures. However, without the prerequisite, i.e. ethical sensitivity, the application of the content and procedural knowledge is likely to fall short of expectations. In the case of ethical or moral sensitivity the person knows that the issue is present (or is asked explicitly to look at an issue).

Developing ethical sensitivity includes 1) learning about the codes, norms and rules that exist outside the person; 2) socialisation process (adhering to the values, norms and rules of the academic community); and 3) motivation and involvement in processing the information (seeing the issue in the context) (Löfström 2012; Rissanen \& Löfström 2014; Sparks and Hunt 1998).

Research has shown that moral/ethical sensitivity/awareness can be developed (cf. Rest 1986; Bebeau et al. 1985; Jordan 2013). There are various pedagogical strategies that have proven to be effective in teaching ethics and developing ethical sensitivity. In particular, use of moral/ethical dilemma cases has been found to be efficient in ethics education (Zucchero 2008; Fisher and Kuther 1997). Case-based learning can be used in most fields where students engage in real-life dilemmas (Biggs and Tang 2007). Effective ethics training is focused on facilitated ethical discussion in peer groups about potential or real ethical dilemma (Jordan et al. 2013). Dealing with cases enhances understanding of the topic, and helps putting theory into practice, facilitates understanding of the context, and enables collaboration. Even small-scale ethical interventions (like discussing cases) have been shown to be beneficial for learning (Clarkeburn 2002). Case-based learning is considered more efficient than traditional lectures and also more enjoyable from the learner's point of view (Kim et al. 2006). Kim et al. (2006) have synthesised the following criteria for good teaching cases: relevance (including taking into account the competence level of learner, goals and objectives, setting of case narrative); realistic setting (including authenticity, distractors, gradual disclosure of content); engagement (including rich content, multiple perspectives, branching of content); challenge (including difficulty, (un) familiarity of the case, case structure, quantity of cases), and an instructional aspect (does the case build upon prior knowledge, assessment method, feedback mechanism, and teaching aids).

Working in groups and cooperating/collaborating has been shown to improve critical thinking skills (Smith et al. 2005; Cavanagh 2011), develop understanding, and help learners relate new concepts to previous knowledge and experiences (Biggs 1999). This applies also to the teaching and learning of ethics and integrity. For instance, working in groups and collaboration increases students' awareness and concerns for academic misconduct and enhances personal integrity and mutual trust (Smith et al. 2005; Cavanagh 2011). However, group work and cooperation requires structuring, facilitation and support (Biggs and Tang 2007; Johnson and Johnson 1999) in which the facilitator initiates, organises and coordinates the collaboration, and is aware of how the activities enhance mutual learning. Scaffolding provides one perspective into supporting group learning processes (through structuring the tasks and providing face-to-face support).

Scaffolding is a teaching strategy providing assistance to students when needed and fading as the learner gains competence (Vygotsky 1978; Wood et al. 1976). The notion of scaffolding provides a suitable lens for understanding group learning processes on 
the topic of research ethics and integrity in which ethical sensitivity is the prerequisite for the initiation of a solution-oriented learning process.

To sum, research shows that case-based learning as well as collaboration are efficient strategies for developing ethics competencies. However, we know less about what takes place in terms of the learning process and development of thinking during case-based learning session. To pinpoint how cases facilitate learning, and to better understand the processes that students engage in while working on ethics cases, we posed the following research questions:

- RQ 1. How is degree students' ethical sensitivity displayed during collaborative case-based learning?

- RQ 2. How does ethical reasoning evolve in terms of levels of understanding during collaborative case-based learning?

- RQ 3. What are the similarities and differences between students at different degree levels in displaying ethical sensitivity in a group learning context?

\section{Pedagogical intervention}

A research ethics workshop was designed integrating cases, collaboration and scaffolding. The focus of the workshop was to give basic knowledge of ethics and integrity to beginner researchers of four phases of research: planning, conduct, dissemination (publishing) and data management. The design of the workshop provided opportunities for development of ethical sensitivity. We use the term 'case' to denote situations with implicit or explicit, actual or potential ethical dilemmas. In some instances, the groups were asked to relate the case to their own context to make the case more applicable for their field.

The topics for the cases were based on the European Code of Conduct for Research Integrity (ALLEA 2017) and the design of training material followed the gradual development of ethical sensitivity, where the initial stage was to trigger ethical sensitivity, then the topics (in the form of questions) were presented to be solved with the support of the group and additional material. Group presentations gave a chance to develop ethical sensitivity even further with the support of one or two facilitators providing more scaffolding as needed by the groups. The design of the training material also supported all the participants to learn about all the cases presented during the training - e.g. if all 5 cases were presented during the training, the participants were encouraged to join in with questions and comments to develop their own understanding of other groups' cases. This way the students could cover the major topics present in the ALLEA code.

The workshops followed a predefined structure (to provide structural scaffolding) with a prior task, working on the case, presenting it and reflecting on learning:

1) Pre-practice questions were designed to attune the students for the topic and map their initial awareness.

2) Task 1 - groups received a case with relatively general and open-ended content (See Appendix 2 for the topics). They were asked to come up with an example related to their field (the cases were applicable for different fields) and to 
define a context to the ethical issues. The first step was to mark on the report sheet (underlying/circling/taking notes) which ethical issues they recognised (both explicit and implicit). The group had about $15 \mathrm{~min}$ for this. The following excerpt illustrates an implicit potential case:

The research institution turns to you to take over a part of a bigger survey as part of an European research project. The subjects of your research will be girls in their early teens (as an alternative - you are collecting data from a sensitive sample - rare artefacts/endangered plants), the results will be published in an international journal. You agree and start your planning. Which ethical issues might emerge?

3) Task 2 - the groups were given guiding questions about the case drawing attention to various issues (topics) characteristic of the research phase, i.e. planning, conducting or publishing. The topics students were expected to discuss were based on contents in the ALLEA Code of Conduct for Researchers. The groups were prompted to utilise the European and the national codes of conduct. The groups had about 20-30 min to discuss the questions. For example, for the case above, some of the questions were:

Which codes of conduct do you follow? Are you familiar with them? Where to find them?Are there special requirements and protocols for handling under-aged human research participants? Is an ethics review required? What determines this? Envision the impact of the research - What is the impact of your research on research participants and other parties?

4) Task 3 - the group was given support material - outlining the topics of the case accompanied by comments and references to rules and regulations pertaining to them, the groups elaborated the answers (in a different colour), the groups spent about $15-20$ min on this.

5) Task 4 - the groups gave overviews of their cases to other groups (thus covering all the phases of research) - this task was scaffolded by one or two facilitators who tried to help the group develop the understanding further. All other students were encouraged to join in with questions and comments. Each group spent about 15 min on the overview.

6) All students who participated in the workshop were asked to fill in a feedback form (individually) in order to identify awareness development and students' perceptions of their learning.

\section{Research method}

In order to address our research questions, 6 workshops were organized with beginning researchers. These workshops followed an action research approach (Stringer 1999) doing a systematic, reflective study of the pedagogical intervention, and the learning process. During the workshops, the main facilitator followed a participant observation 
technique (Kawulich 2005) enabling the researchers to learn about the activities of the people under study in an authentic learning setting. For the data analyses we adopted a mixed method approach, combining quantitative and qualitative techniques.

\section{Context}

In the Estonian higher education system, studies for a bachelor's degree take 3 years, with an additional 2 years necessary for a master's degree. A bachelor's degree equals 180 credits ( 1 credit in the European Credit Transfer System equals approximately $26 \mathrm{~h}$ of study), and a master's degree additional 120 credits. Doctoral programme lasts nominally for 4 years and equals 240 credits (out of which 180 credits are nominated for research work).

All BSc students lead an individual research project that forms the experimental part of their written final thesis. Bachelor curricula students' studies can culminate either with the defence of literature overview analysis or experimental thesis. In addition, bachelor students in Educational Sciences are expected to conduct small scale research which may include children. For graduation, the master's students in Natural Sciences curricula as well as Educational Sciences write a research thesis equivalent to one research paper and are encouraged to publish in scientific journals. Both the undergraduate and graduate theses work can require the acquisition of ethical permits.

\section{Participants}

Data were collected during 6 workshops taking place in 2018, where the different cases (C1 to C5) were tested (see Fig. 1). The participants were 64 students: 31 bachelor (BA/ $\mathrm{BSc}$ ), 20 master (MA/MSc), and $13 \mathrm{PhD}$ students organised in 19 groups during the workshops. All participants were students at one Estonian university with social and behavioural sciences as well as natural science backgrounds. We have included both MA/MSc and $\mathrm{PhD}$ students in the study, as in the Estonian context also master students engage in research work and it is often at this level of studies that an interest for research and continued studies is sparked. While bachelor students do not engage in independent research, they are expected to understand central concepts including those related to research ethics, and to produce a bachelor thesis reflecting their understanding of processes of knowledge creation in their field.

\section{Research ethics}

The research followed the European Code of Conduct for Research Integrity (ALLEA 2017) and the Estonian National Code of Conduct (Hea Teadustava 2017). The

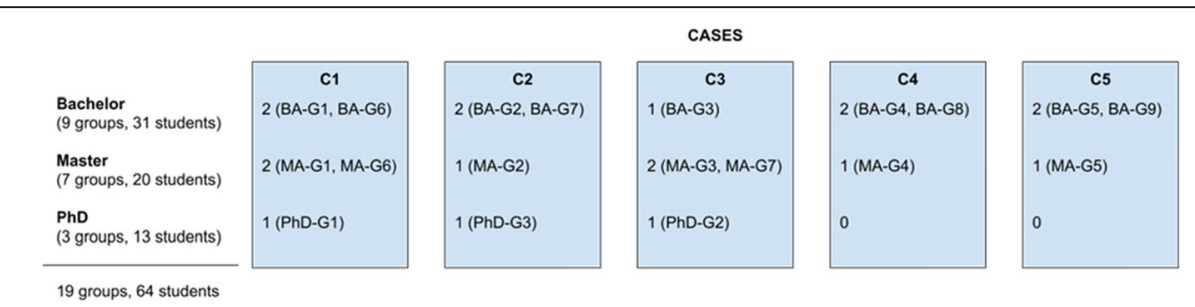

Fig. 1 Distribution of students across groups and cases 
participants were asked for their informed consent prior to data collection. Participation was voluntary, and the decision not to participate in the research was not to influence the participants' status in the course or in their studies. Participants had the right to withdraw their consent at any time. The data were anonymized before analyses. The Estonian code of conduct does not provide guidance on ethics review, and there are no other guidelines in Estonia for non-medical research involving human participants. Therefore, as two of the authors are affiliated with a Finnish university, it appeared reasonable to apply the Finnish National Board on Research Integrity guidelines (2009) for research in the humanities and social and behavioural sciences. According to these guidelines, a study such as the one presented here does not require an ethics review. Ethics review is required when a study involves an intervention in the physical integrity of research participants; deviates from the principle of informed consent; involves participants under the age of 15 being studied without parental consent; exposes participants to exceptionally strong stimuli; causes long-term mental harm beyond the risks encountered in normal life; or signifies a security risk to subjects (Finnish Advisory Board on Research Integrity 2009). None of these conditions were met in this study.

\section{Data collection}

Data consisted of the following materials:

\section{Collaborative group report}

These were short (approx. one page) written reports produced by the groups. Each group produced one report making a total of 19 reports. The report paper had initially a case written on it, and the groups added an analysis of the case.

\section{Video and audio recording of group presentations}

Groups orally reported what they had written in the group report. The oral presentations were recorded either using video or audio recording. A total of $6 \mathrm{~h}$ and $26 \mathrm{~min}$ of recordings were transcribed verbatim. During the presentations two teachers supported the group (in case they had misunderstood or missed an important issue).

\section{Individual feedback forms}

After the workshop students filled in feedback forms in writing and individually. In total 51 feedback forms were returned. There were questions of various types - 3 multiple choice questions asking about the level of tasks, its clarity and the role of the group; there were 2 yes/no questions about the efficiency of the workshop and two open-ended questions asking for individual perceptions of the ethics workshop and recommendations for improvement.

\section{Observation notes}

During the workshop, the observer (who was one of the facilitators) took notes in the observation diary on student answers given during the warm-up task, how groups 
appeared to be working collaboratively, as well as any problems or ideas of the facilitators. After each workshop general comments were added on the outcomes.

Group reports and presentations gave input to RQ 1,2 and 3. Feedback forms and researcher's observation notes informed only RQ 3.

\section{Analyses}

Group reports and presentations were analysed qualitatively. Individual feedback forms were analysed quantitatively using descriptive statistics. Observation notes were not analysed per se, but they were used as supporting material for the other analyses.

We applied the Structure of the Observed Learning Outcome, the SOLO taxonomy, (Biggs 1999) for analysing the learning processes. The explanation and our interpretation of different SOLO levels are described in Appendix 1. Shortly (Biggs 1999):

- At the pre-structural level, the learner has not yet approached the issue in a meaningful way, but is simply repeating the words in the question without understanding them.

- At the unistructural level, the learner has sufficient knowledge to identify, recognise, count, find, label, match, name, and perform simple procedures. The learner has mastered one relevant aspect - dealing with terminology, completing part of the task, defining concepts - but not others.

- At the multistructural level, the learner has understood several aspects but is unable to relate them to one another. The learner can enumerate, describe, illustrate, sequence, select, combine, and follow procedures, but struggles to make connections between them or draw conclusions based on interrelationships.

- At the relational level, relevant aspects are integrated into a coherent structure. The learner is able to address the point and provide explanations, give details, and connect to the whole, offering relevant examples.

- At the extended abstract level, the coherent whole is generalised or reconceptualised at a higher level of abstraction. The learner grasps a more abstract version of the concept, and recognises other domains to which the concept might be applied.

As part of the analysis, an Ethical Case Assessment Grid (ECAG, see Appendix 3 for the template) was developed based on the SOLO taxonomy. The facilitators used an ECAG sheet and topic legend for each case report - analysis of the reports took no more than $5 \mathrm{~min}$ a case and the final task was evaluated during oral presentations. Across the case and across the degree level analysis showed that the 'accelerated' method gave similar results to the detailed method (carried out based on written reports and transcriptions of presentations). Eventually, the group work results were evaluated during the training and at the end of the workshop participants were given instant feedback on their progression and topics they had identified as well as additional perspectives relevant in considerations of the case.

To display ethical sensitivity, group reports and presentation data were indicated in the ECAG grid. The content of the reports and presentations were divided into topics based on the ALLEA code of conduct (deductive analysis) and indicated in the grid. 
To identify the different stages of their work, the groups were asked to use different colours during different tasks of the workshop. Since the learning activities and the reports were carried out collaboratively, the analysis focused on the group rather than on individual level.

The analysis was conducted on three levels: topics, group performance and case overviews. To illustrate how the topic analysis was carried out, we take as an example one of the MA groups (MA-G1) which worked on a case dealing, among other ethics topics, with "Topic 1 - Knowledge of the codes of conduct (which ones to use and where to find them)" and "Topic 2 - Requirements/necessity of ethics review". Table 1 illustrates how, based on the group (MA-G1) responses to the different tasks, we inferred the SOLO level of the group understanding in each task. While during the group work (tasks 1 to 3 ) the evidence came from the comments and notes written by the students in their reports, for Task 4 (oral presentations) the topics were identified in the presentation transcripts. In those cases when the students did not spot the ethics topics, the facilitators prompted the discussion during Task 4, and the group answers were taken into consideration.

Figure 2 visualizes the group performance, showing how this one particular group (MA-G1 dealing with case C1) progressed during the workshop in the different topics covered by the case they had been assigned. As can be seen not all topics were recognised during Task 1 (topics 3-6). Task 2, asking the questions and drawing attention to the ethical aspects, helped the group notice most of the topics and most of them even on the multistructural level. In task 3 the group was provided with support material to learn more about the topics, and some topics reappeared in the group's answer. In Task 4, oral presentation and simultaneous scaffolding, the group showed gain in one topic, but it was also discovered, that they had misunderstood one topic, which displays as a drop on the graph.

Once all the groups were analysed, we aggregated the data per case, obtaining case overviews. This analysis helped us to identify commonalities and discrepancies among groups working with the same cases. It is not possible to directly compare

Table 1 Example of topic analysis

\begin{tabular}{|c|c|c|c|}
\hline Topic & Task & Student response & SOLO level \\
\hline Topic 1 & 1 & $\begin{array}{l}\text { Highlighted text: [...] Project [...] European project [...]. } \\
\text { Comment: " What exactly is the aim of the project?" }\end{array}$ & Unistructural \\
\hline Topic 2 & 1 & $\begin{array}{l}\text { Highlighted text: [...] Girls in their early teens [...]. } \\
\text { Comment: "Vulnerable group of minors; research permits; } \\
\text { consent from the girls/parents; ensuring confidentiality." }\end{array}$ & Multistructura \\
\hline Topic 1 & 2 & $\begin{array}{l}\text { Comment: "All the aspects of the code of conduct (e.g. Hea } \\
\text { Teadustava; code of conduct, etc). Yes; from the internet." }\end{array}$ & Unistructural \\
\hline Topic 2 & 2 & Comment: "Yes, as they are minors thus a vulnerable group" & Multistructura \\
\hline Topic 1 & 3 & Comment: " European Code of Conduct of Research Integrity & Multistructura \\
\hline Topic 2 & 3 & $\begin{array}{l}\text { Comment: " Can this research be published in the chosen } \\
\text { journal? [requirements to be checked]" }\end{array}$ & Multistructura \\
\hline Topic 1 & 4 & $\begin{array}{l}\text { The students mentioned various codes of conduct, and } \\
\text { the need to use the international codes as the project was } \\
\text { EU guided }\end{array}$ & Multistructura \\
\hline Topic 2 & 4 & $\begin{array}{l}\text { The group showed some discrepancies regarding the need } \\
\text { of informed parental consent }\end{array}$ & Unistructural \\
\hline
\end{tabular}




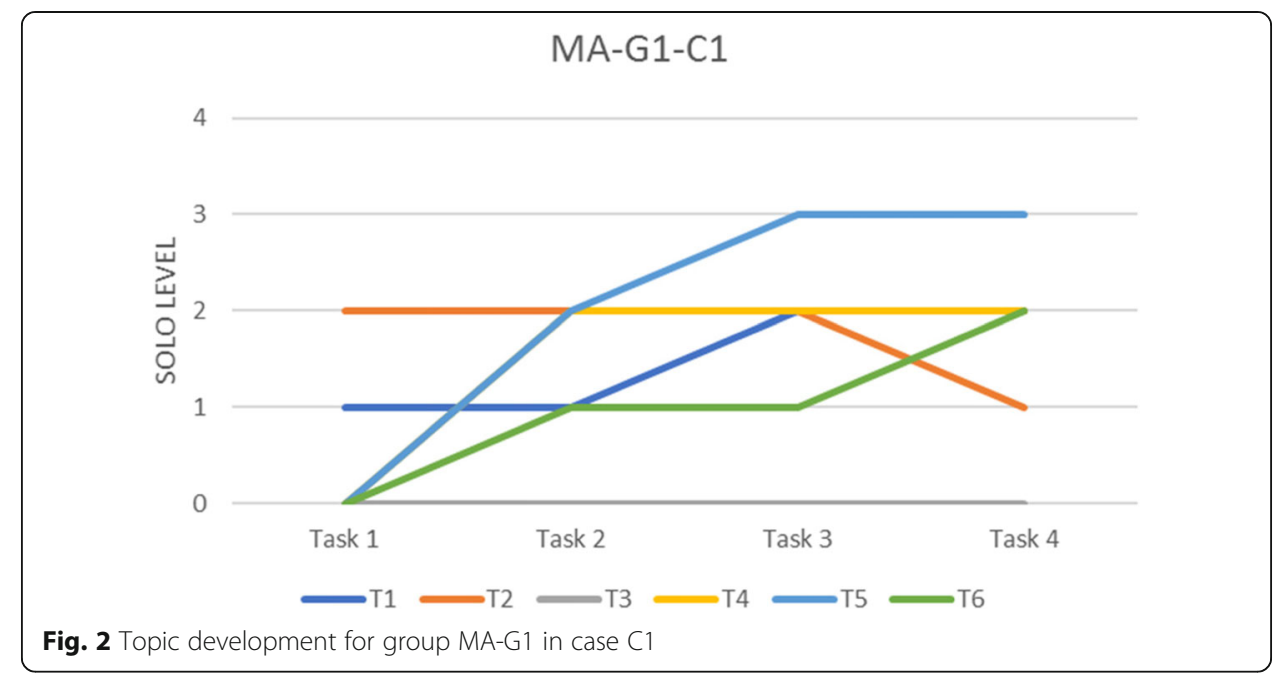

the five cases based on the groups' learning processes, because the cases were different. For example, case C5 involved more factual questions while the other cases offered opportunities for more explorations of different solutions. In addition, we did not evaluate whether the groups reached the 'roof' of their understanding. It might be possible with different kinds of tasks to achieve even higher levels of understanding.

\section{Results}

It was possible to identify display of ethical sensitivity of student groups on all levels of the SOLO taxonomy among all BA/BSc, MA/MSc and $\mathrm{PhD}$ groups. The groups exhibited learning on different SOLO levels during different phases of their group work (see Appendix 1).

\section{Display and evolvement of ethical sensitivity}

During collaborative case-based learning all groups displayed some ethical sensitivity, and the understanding of ethical issues increased in terms of levels of understanding. The display and evolvement of understanding is presented based on tasks (1-4).

As students received their case, in some instances they first had to specify the context for it (cases $\mathrm{C} 1$ and $\mathrm{C} 2$ ), and then were presented with the first task, where they were prompted to identify ethical issues. The groups displayed their understanding by underlining the words in the cases, sometimes highlighting or circling. Some groups even added explanations and examples exhibiting their knowledge, e.g. "girls in their early teens: vulnerable group of minors".

Results of Task 1 indicated that only a few topics were more apparent to some groups than others, e.g. the most commonly displayed topic was the conflict of interest (in the case of knowing the reviewer). This was closely followed by recognising the necessity of the ethics review (in case of vulnerable population), the relevance of not neglecting negative results, who can claim authorship of a publication, how the chosen method may influence the sample, and the procedure for the informed consent. Out of 35 ethics sub-topics introduced in the cases (see 
Appendix 2) there were 22 topics that were not recognised at all by groups during the first task. The reason might be that many ethical issues are implicit and not so clear after first examination of the case.

It was difficult for students to recognise more subtle (and even some very basic) topics, which made Task 2 crucial. By wording the topic in the form of a question all topics were recognised by groups. Indeed, about a third of groups could not answer all the questions presented during Task 2 immediately, but they kept the issues in mind and were able to utilise the support material to find the answer in the next task. For factual questions, the groups often reached unistructural level, e.g. for the question about which codes of conduct should be used, the groups often said, for instance: national code of conduct, ALLEA, can be found for example online. Even if the topic was recognised in the first task, most groups who did, were able to add an explanation and progress to a higher level of understanding. For instance, on a question about how to treat your research participants and colleagues, one group had recognised the topic already during Task 1 and reached unistructural level. When they got the questions they elaborated: [treating everyone] according to the codes of conduct, respect, keep confidentiality, be honest, find a trusted contact.

Indeed, there were some instances where there was fluctuation between SOLO levels from Task 1 to Task 2. For instance, one group in Task 1 showed awareness of importance of data management in case of delicate information, but in Task 2 when prompted about the necessity of a data management plan, they responded "It is necessary to have specially trained staff. Data management system needed", failing to address the issue asked for. On occasions groups seemed to display understanding but with further prompting it became apparent that they had misunderstood the topic or were advancing in a non-relevant direction.

Progressing to Task 3 groups were provided with support material, which explicitly described the topics in the ALLEA Code of Conduct, explanations to topics and links for further reading. Results indicated that the greatest gain from support material came to the topics related to data management (there were 11 sub-topics related to data management with nine showing gain), as this case contained mostly factual questions and answers could easily be found. The topic development of case C5 (data management) is illustrated in the Fig. 3 below. Almost all the groups showed gain between Tasks 2 and 3:

The finding of fluctuation of display of understanding of research ethics and integrity may be the result of various factors. Many factual questions were provided with answers in the support material, e.g. information about the codes of conduct, necessity, procedure in case of conflict of interest, publishing criteria, and so on. On the other hand, the gain was smaller or non-existent with questions that required more contemplation by the groups (analytical questions). This was also anticipated as students often expected ready-made answers to questions they struggled with and that might require analysis of information. For instance, one group wrote about a topic -'which steps should you take in case of misconduct': "Explain the research to the participants "Get a written consent "Explain data protection (who can see) "Confidentiality and anonymity - how is ensured? "Eliminate risks "Ensure voluntary participation and the right to withdraw "Explain again 


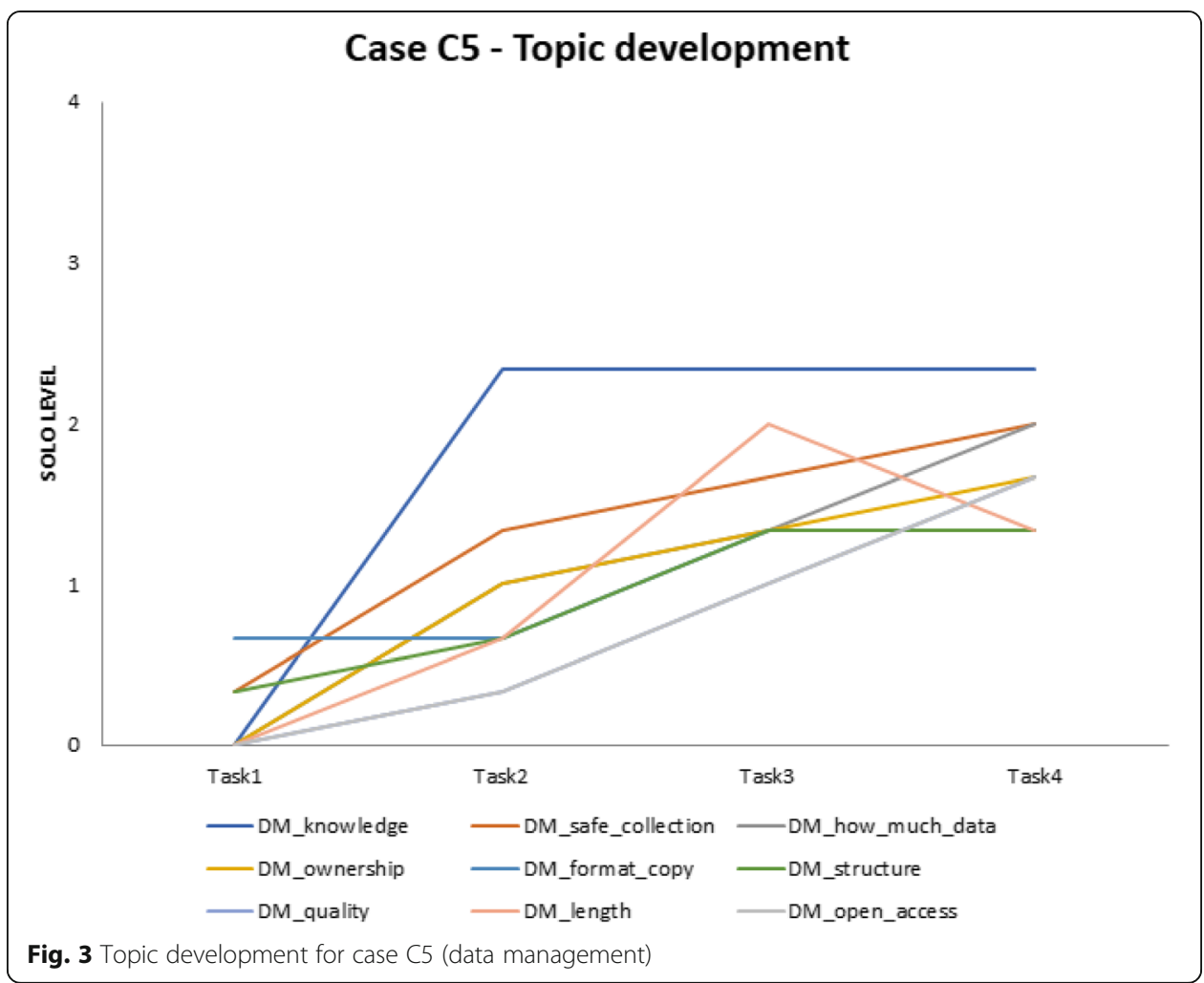

what is about to happen". The group just listed the steps for getting an informed consent, not the steps to be taken in the case of misconduct (they were expected to come up with their original answer). It can be assumed that they expected ready-made answers to the questions from the support material and did not work on drawing conclusions.

In the display of topics in Task 4 (oral presentation of the group work) the analysis showed the gain for topics that required more contemplation. At this point, oral scaffolding was provided by one or two facilitators. Factual questions generally remained at the level of the previous task. The biggest gains were identified for topics concerning misconduct, publishing issues, negative results, evaluation of the impact of the research, and minimising risks and harms. Many of these topics may have several answers, and require ethical deliberation. In Task 4 the scaffolding helped students recognise ethical aspects they had not thought about before and develop their understanding even further. For instance, one group (BA-G3) dealing with a case of misconduct (senior researcher claiming authorship in an article he/ she has not contributed to) showed quite rapid development of understanding of Topics 2, 3, 5 and 6 during presentations. The following dialogue provides an example of the scaffolding provided by the facilitator and the group responses (translation from Estonian):

A group member speaks on behalf of the entire group (BA-G3-P1): "We discussed it in the group and .... First we could ask the senior researcher what the problem was and then explain how this is not ethical. Then turn to the council or board of the 
institution that would help us solve the problem by discussing the issue, And the next question is - who could we turn to to get help? Ummmm ... yes, then to the research institution and then the lawyer" [end of the sentence not clear].

Facilitator: "I would ask you - if this article you are discussing is part of your MA thesis and the senior researcher in question is a member of the defence board - would it be easy for you to have this conversation?"

Student (BA-G3-P1): "It might not be easy, but at the same time, if there is the national code of conduct for researchers where the ethical aspects have been written down ... the ones he/she is violating, then probably our research is more important ... our findings are more important .... We have conducted that research and if he is just a member in that board or a reviewer then he/she has no right to use his position to have his/her name on our work."

Facilitator: "OK, but let's assume that you are the MA student who has had a conversation with that senior researcher that after your graduation there will be a vacancy of a junior researcher for you."

Student (BA-G3-P1): "So that he/she would be convincing me ... that he/she would be returning the favour? That is the ethical conflict!"

Facilitator: "How would you solve the problem? Would you feel on the safe ground?"

Student (BA-G3-P1): "Well, I think there is no choice for either side, as, first of all, his/her offer for taking the research and me getting the position - this is by no means ethical. And then me accepting the position - this lacks any kind of ... Justice, so to say."

The previous example illustrates how ethical sensitivity is clearly present, the students just needed a bit 'nudging' to expand the case. To illustrate, initially the presenter just listed possible instances to turn to, but not really seeing the relation between them (multi-structural level). Following that, a facilitator extended the case by introducing another aspect to consider which led the presenter to analyse the situation again and find support for the argument. Another extension introduced the next topic, and as the sensitivity was already triggered, the topic of the conflict of interest was noticed immediately. The direct questions by a facilitator resulted in a balanced argument by the presenter.

\section{Similarities and differences between degree levels}

Different degree levels advance non-linearly in ethical understanding and require different forms of support. The data were drawn from task-based results (see the previous section), observation notes and the feedback forms, where participants reflected on the group work and learning.

Bachelor students started on a pre-structural level for almost all topics, which was expected considering their very limited exposure to research ethics. Wording the ethical issues in Task 2 helped beginners reach unistructural level. Support material 
further helped about a half of groups to reach a multistructural level. For bachelor students, oral scaffolding (Task 4) was the most beneficial as they exhibited the most gain during this task. Observation notes also revealed that BA/BSc students were open to new ideas, did not get stuck with details, and were creative to invent a context. Feedback forms showed that while more than $90 \%$ of bachelor students found the level of difficulty of the tasks average, about a third of the students thought certain parts of the material were unclear. Their challenges were mostly related to terminology, lack of knowledge of where to access information and lack of research experience. Almost all the students claimed that working collaboratively was a big help and case-based collaborative learning had improved their ability to identify ethical issues better in the future (i.e. ethical sensitivity).

Master students started at almost the same level in the SOLO taxonomy as bachelor students, but possibly due to more knowledge and experience in research, Task 2 helped most groups reach unistructural or multistructural levels. Support material and oral scaffolding contributed only slightly to their understanding. Observation notes and feedback forms also indicated that master students found it more difficult to identify the context. They would have preferred to have more details provided in the task itself. Also, the relatively minor gain during Task 4 was unexpected as master students received more than twice as much oral scaffolding compared to bachelor students (times of prompting were counted in the transcripts). Oral scaffolding was provided by facilitators based on the need of students. In case there was no progression in the group, more scaffolding was provided. Overall, bachelor and master students reached almost the same level of understanding, i.e. nearly the multistructural level, which is also considered a threshold. Based on the feedback forms master students considered the level of difficulty average or easy, they also considered the tasks clear. All master students claimed that group-work was very efficient and helped them see different points of views.

$\mathrm{PhD}$ students progressed the most. $\mathrm{PhD}$ groups started on different levels, mostly between pre-structural and unistructural levels. They gained the most from Task 2 on wording the ethical issue, which helped the groups reach the multistructural level. Support material in Task 3 only helped a little and oral scaffolding was practically not needed. Groups showed increased understanding of only in a few topics during the presentation task. Observation notes and feedback forms indicated that while $\mathrm{PhD}$ students considered the level of tasks average, they reported being confused by the case. They got stuck on uncertainties, and speculated on things that were not relevant for the case. Nevertheless, they also thought that group-work was an asset and working in groups was more efficient than listening to a lecture.

Generally, bachelor students lacked the knowledge and experience, at the same time exhibiting high sensitivity for ethical issues and potential for development when provided with appropriate support. MA/MSc groups had difficulties seeing the 'bigger picture' of the case and getting stuck on detailed aspects of the case. $\mathrm{PhD}$ groups differed from the master level groups in that after the first reading of the case they requested more information instead of inventing the context themselves (which was part of the task). The difficulty for the PhD students was the fairly open nature of the cases. Due to the limited information in the cases the 
discussions became speculative and side-tracked. This can be seen as an effort to extrapolate hints in the cases and to draw some more general conclusions. The role of the group proved to be efficient for all groups. The participants highlighted in their feedback forms that discussions, peer explanations, help with translating, answering questions together, and expressing different points of views as aspects distinguishing group work as beneficial.

\section{Discussion and conclusions}

The current research supports findings that case-based and collaborative learning is efficient in developing ethics competencies, as also indicated by Rissanene \& Löfström (2014), Clarkeburn (2002) and others. Our aim was to scrutinise the anatomy of learning processes during collaborative case-based workshops of such pedagogical intervention by utilising the SOLO taxonomy. The posed research questions were: how is ethical sensitivity displayed and how does it evolve among degree students; and what are the similarities and differences of degree students' evolvement.

The analysis of the groups' ethical reasoning in relation to SOLO levels shows that groups gradually developed their reasoning towards higher levels of reasoning, but not all groups reached levels beyond the multi-structural level. Similarly, Löfström (2012) found that both master and doctoral students may fail to recognize ethical issues beyond the multi-structural level. Bachelor students seemed to lack knowledge and research experience, at the same time exhibiting high sensitivity and potential for development when provided with appropriate support. Observation notes also indicated that groups that seemed to work more actively together achieved higher levels of understanding, but group dynamics was not in the focus of the present research.

Generally, cases of the workshop are somewhat individual instances - case descriptions were quite general and groups were asked to invent their own context for their case (to make it relevant for their field). Nevertheless, the cases are comparable as the training design follows the same pattern - there are cases relevant for various phase of research, there is a number of topics (between 6 and 9), their display and progress can be evaluated. Indeed, the topics of the cases have different value (e.g. some topics just require factual knowledge while others demand more thorough contemplation, we called them 'factual' and 'analytical' questions), so it would not be appropriate to expect higher level of understanding of all the topics - the main aim was to evaluate how the progress of topics within the case happened.

Wording the ethical issue was a crucial step in triggering ethical sensitivity. Prior research has also demonstrated that by wording the ethical issue the person becomes aware of it and is thus able to proceed to recognising different stakeholders and possible courses of action (Rest 1986; Myyry 2003; Morton et al. 2006).

In addition, results indicated that development of understanding of topics that were factual in nature was more efficient with the help of additional reading material, while more analytical topics benefited more from group discussions and, in case of BA students, oral scaffolding.

There were instances where there was fluctuation between SOLO levels appearing as a "backward" step. Prior research (Löfström 2012; Butterfield et al. 2000) distinguishing between ethical awareness and ethical sensitivity suggests that 
ethical awareness, although a prerequisite for ethical problem-solving, does not necessarily translate into a deeper understanding of the ethical issue itself. Such backward fluctuation has been explained by Rissanen and Löfström (2014), Sparks and Hunt (1998) and Niemi (2016) as a possibility of routinisation: when people get used to certain tasks they do not check them as thoroughly any more, fall into routine. We are assuming that sensitivity towards ethical issues might be higher during BA level, as they are not 'routinised' yet, which is also outlined in the literature (Rissanen and Löfström 2014; Sparks and Hunt 1998; Niemi 2016). Another possible explanation offered by Niemi (2016) and Kvalnes $(2014,2019)$ is the situational variation and subsequent moral neutralisation. Both authors (Niemi 2016; Kvalnes 2014, 2019) point out that situational and environmental variation are often underestimated but have a great influence on ethical conduct of people, possibly also ethical sensitivity. For instance, if the environment does not support integrity or encourages unethical behaviour then the students in that environment will learn to do the same and see it as 'normal' conduct (or fail to see certain ethical aspects). In addition, in certain situations students may use various moral neutralisation techniques (Kvalnes 2014, 2019) to justify misconduct (e.g. denial of responsibility or appeal to higher loyalties). Both authors (Niemi 2016; Kvalnes 2014) point out that being aware of such challenges in the research community may alleviate the threat of misconduct - this would include systematic ethics training, open discussions and creating the working environment that would support academic integrity.

While the research allowed us to identify group learning processes during the solving of ethics cases, future research should analyse the nature of scaffolds that groups may need in order to advance in their task.

\section{Educational implications}

Using Action Research as a methodological approach in this study has contributed to deeply understand the learning process taking place in the groups of students. However, it should be noticed that given that this research methodology is "contextbound", the research questions (and our answers) may not be very generalizable.

In terms of analyses, the SOLO taxonomy has helped us to evaluate how the student understanding of ethics topics evolved during various tasks of cases. According to our experience, this instrument could be useful for other facilitators to assess the evolvement of topics present in ethical cases. Even more, to make the assessment of progression smoother, learners could use pre-prepared template slides that have different sections for different tasks. This will help facilitators pinpoint the level of understanding more easily and give feedback to the group.

Drawing on these results, to help facilitators and learners of research ethics courses, we have created an Ethical Cases Assessment Grid (ECAG) - a tool to evaluate students' understanding and its progress of ethics cases during collaborative groupwork (see Appendix 3; for a filled ECAG see Appendix 4). In the future, we will explore how to enrich the grid with a visualization that shows topics and their progress. The tool will help facilitators evaluate the progress of understanding, give instantaneous feedback to groups, and make recommendations on which topics to cover again or more thoroughly. 


\section{Appendix 1}

Table 2 SOLO taxonomy explanation

SOLO taxonomy
level, image (Hook
level, image (Hook 2011)

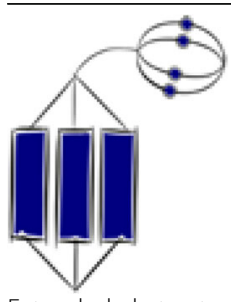

On the extended abstract level the coherent whole is generalised or reconceptualised to a higher level of abstraction - the response goes beyond conceptualising, higher level of abstraction with application to new and broader domains.

Extended abstract level

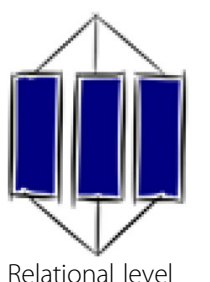

On the relational level relevant aspects are integrated into an overall coherent structure - ability to address the point and provide explanations, give details and connect to the whole, giving relevant examples.

On the extended abstract level, groups went beyond conceptualizing the present issue making steps towards relating the ethical issues to applications beyond the present case.

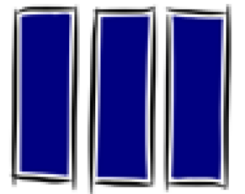

Multistructural level

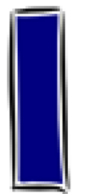

Unistructural level

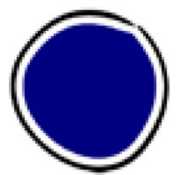

Pre-structural level
On the multistructural level several aspects have been understood, but not relating them to one another - ability to enumerate, describe, illustrate, sequence, select, combine, follow procedures, but struggle to make the connections between them or draw conclusions based on interrelations.

On the unistructural level knowledge enables learner to identify, recognise, count, find, label, match, name, perform simple procedures. One relevant aspect is understood - dealing with terminology, meeting part of the task, defining concepts while some aspects still missing.

On the pre-structural level the issue is not approached in a meaningful way - repeating the words in the question/ simulation/ code; no understanding.
On the relational level, groups displayed an ability to address the most relevant ethics issues and provide explanations pointing out interrelations and providing examples demonstrating own reasoning.

On the multistructural level, the groups demonstrated that concepts had been understood appropriately, but struggled to make connections between them and to draw conclusions based on any interrelations.

On the unistructural level, the groups identified one relevant aspect displaying some familiarity with relevant concepts, but failing to address some more pertinent dimensions of the case.

On the pre-structural level, the groups failed to identify a relevant ethical perspective or they identified an issue, but did not approach it in a meaningful way, repeating the words in the case without displaying evidence of own processing. 


\section{Appendix 2}

Table $\mathbf{3}$ Table with topics

\begin{tabular}{|c|c|c|c|}
\hline Topic & Sub-topics (code) & Sub-topics explained & $\begin{array}{l}\text { Cases with } \\
\text { the topic }\end{array}$ \\
\hline BEN - Benefit & BEN_who & Who will/should benefit & $\mathrm{C} 2$ \\
\hline CC - Codes of conduct & CC_knowledge & Knowledge of the codes of conduct & $\mathrm{C} 1$ \\
\hline \multirow[t]{2}{*}{$\mathrm{Cl}$ - Conflict of interest } & Cl_knowing_reviewer & $\begin{array}{l}\text { Conflict of interests - knowing the } \\
\text { reviewer }\end{array}$ & \multirow[t]{2}{*}{ C4 } \\
\hline & Cl_steps & $\begin{array}{l}\text { How to notify of the conflict of } \\
\text { interest }\end{array}$ & \\
\hline DA - Data analysis & DA_transparency & Data analysis transparency & $\mathrm{C} 2$ \\
\hline \multirow[t]{11}{*}{ DM - Data management } & DM_format_copy & Data format and copy & \multirow[t]{11}{*}{$\mathrm{C} 1, \mathrm{C} 2, \mathrm{C} 5$} \\
\hline & DM_how_much_data & How much data is needed & \\
\hline & DM_knowledge & Knowledge of DMP & \\
\hline & DM_length & Data storage length & \\
\hline & DM_open_access & Is data openly accessible & \\
\hline & DM_ownership & Data ownership & \\
\hline & DM_plan & Data management plan & \\
\hline & DM_quality & How to ensure data quality & \\
\hline & DM_safe_collection & Data safe collection & \\
\hline & DM_storage & Data storage & \\
\hline & DM_structure & What is the structure of data & \\
\hline \multirow{2}{*}{$\begin{array}{l}\text { ER - Ethics review and special } \\
\text { requirements }\end{array}$} & ER_application & Ethics review application procedure & \multirow[t]{2}{*}{$\mathrm{C} 1, \mathrm{C} 2$} \\
\hline & ER_need & Need for ethics review & \\
\hline IC - Informed consent & IC_procedure & Procedure for the informed consent & $\mathrm{C} 2$ \\
\hline IM - Impact of research & IM_evaluate_impact & Evaluating the impact & $\mathrm{C} 1$ \\
\hline \multirow[t]{6}{*}{ MIS - Misconduct } & MIS_alone_help & $\begin{array}{l}\text { Deal with misconduct alone or seek } \\
\text { help }\end{array}$ & \multirow[t]{6}{*}{$\mathrm{C} 3, \mathrm{C} 4$} \\
\hline & MIS_confrontation & Confront the violator & \\
\hline & MIS_procedure & $\begin{array}{l}\text { Procedure of action in case of } \\
\text { misconduct }\end{array}$ & \\
\hline & MIS_republishing & Would you republish the same article & \\
\hline & $\begin{array}{l}\text { MIS_resubmitting_ } \\
\text { minor_changes }\end{array}$ & $\begin{array}{l}\text { Would you resubmit the manuscript } \\
\text { with minor changes }\end{array}$ & \\
\hline & MIS_steps & $\begin{array}{l}\text { What steps would you take in case } \\
\text { of misconduct }\end{array}$ & \\
\hline \multirow[t]{2}{*}{ NR - Negative results } & NR_procedure & $\begin{array}{l}\text { What is the procedure to notify of } \\
\text { negative results }\end{array}$ & \multirow[t]{2}{*}{ C4 } \\
\hline & NR_relevance & $\begin{array}{l}\text { What s the relevance of publishing } \\
\text { negative results }\end{array}$ & \\
\hline OB - Observation/method & OB_issues & Observation issues & $\mathrm{C} 2$ \\
\hline \multirow[t]{4}{*}{ PUB - Publishing } & PUB_author & Who can be the author & \multirow[t]{4}{*}{$\mathrm{C} 3, \mathrm{C} 4$} \\
\hline & PUB_authorship_claim & Who can claim authorship & \\
\hline & PUB_requirements & What are publishers' requirements & \\
\hline & PUB_reviewing & Reviewing manuscripts & \\
\hline RH - Risks and harm & RH_minimise & How to minimise risks and harm & $\mathrm{C} 1$ \\
\hline TR - Treating collaborators & TR_others & $\begin{array}{l}\text { Treating others - partners and } \\
\text { participants }\end{array}$ & C1 \\
\hline
\end{tabular}




\section{Appendix 3}

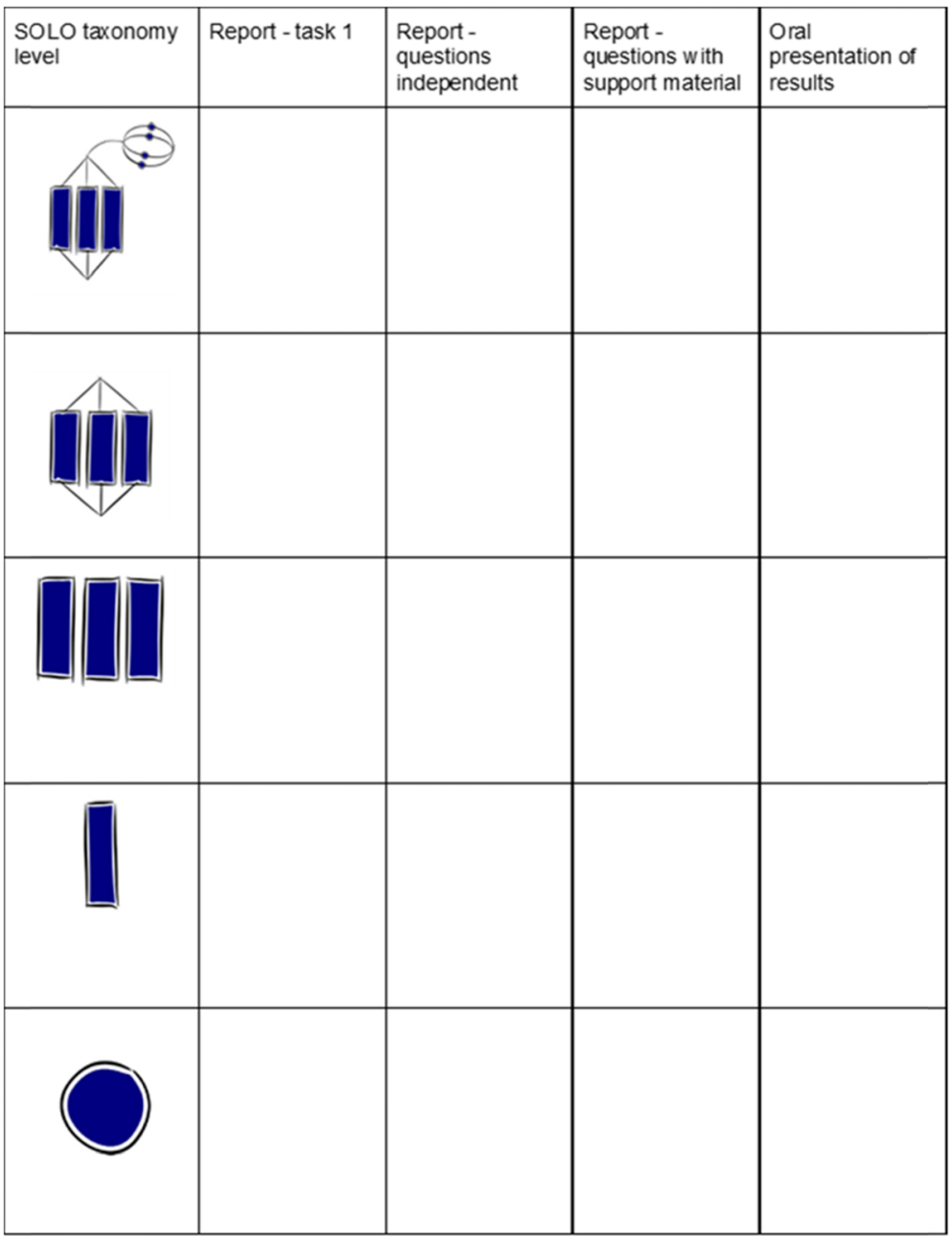

Fig. 4 ECAG template for facilitators. (image: Hook 2011) 
Appendix 4

\begin{tabular}{|c|c|c|c|c|}
\hline $\begin{array}{l}\text { SOLO } \\
\text { taxonomy level }\end{array}$ & $\begin{array}{l}\text { Report - } \\
\text { task } 1\end{array}$ & $\begin{array}{l}\text { Report - } \\
\text { questions } \\
\text { independent }\end{array}$ & $\begin{array}{l}\text { Report - questions } \\
\text { with support material }\end{array}$ & $\begin{array}{l}\text { Video - oral } \\
\text { presentation of } \\
\text { results }\end{array}$ \\
\hline & & & $\begin{array}{l}\text { Potential risks/harm, } \\
\text { how to minimise }\end{array}$ & $\begin{array}{l}\text { Potential } \\
\text { risks/harm, how to } \\
\text { minimise }\end{array}$ \\
\hline & $\begin{array}{l}\text { EU } \\
\text { Project; } \\
\text { Girls in } \\
\text { their } \\
\text { early } \\
\text { teens }\end{array}$ & $\begin{array}{l}\text { Requirements/ } \\
\text { necessity of } \\
\text { ethics review; } \\
\text { Treating } \\
\text { participants and } \\
\text { colleagues; } \\
\text { Potential } \\
\text { risks/harm, how } \\
\text { to minimise; }\end{array}$ & $\begin{array}{l}\text { Knowledge of the } \\
\text { codes of conduct; } \\
\text { Requirements/ } \\
\text { necessity of ethics } \\
\text { review; } \\
\text { Treating participants } \\
\text { and colleagues; }\end{array}$ & $\begin{array}{l}\text { Know ledge of the } \\
\text { codes of conduct; } \\
\text { Treating } \\
\text { participants and } \\
\text { colleagues; } \\
\text { Data management } \\
\text { planning }\end{array}$ \\
\hline & & $\begin{array}{l}\text { Knowledge of the } \\
\text { codes of conduct; } \\
\text { Data } \\
\text { management } \\
\text { planning }\end{array}$ & $\begin{array}{l}\text { Data management } \\
\text { planning }\end{array}$ & $\begin{array}{l}\text { Requirements/ } \\
\text { necessity of ethics } \\
\text { review???; }\end{array}$ \\
\hline & & $\begin{array}{l}\text { Evaluating the } \\
\text { impact of the } \\
\text { research; }\end{array}$ & $\begin{array}{l}\text { Evaluating the impact } \\
\text { of the research }\end{array}$ & $\begin{array}{l}\text { Evaluating the } \\
\text { impact of the } \\
\text { research }\end{array}$ \\
\hline
\end{tabular}

Fig. 5 ECAG for group MA-G1-C1. (image: Hook 2011)

\section{Abbreviations}

ECAG: Ethical Case Assessment Grid; SOLO: Structure of the Observed Learning Outcome

\section{Acknowledgements}

We would like to express our gratitude to Pam Hook for allowing us to use her images of the SOLO taxonomy. We are also grateful to all the participants of the study.

\section{Authors' contributions}

AT created the research concept and designed the training and assessment materials for the research purposes, acquired, analysed and interpreted the collected data, wrote and revised the manuscript. MJR-T analysed and interpreted the data, created the aggregated dataset, visualised the research process and results, substantially revised the manuscript. KK conducted trainings and acquired data, supported research design, drafted and revised the manuscript. EL created the research concept and helped design the training materials, interpreted results, substantially revised the manuscript. All authors read and approved the final manuscript.

\section{Authors' information}

Anu Tammeleht is an analyst of research ethics at Tallinn University and a PhD student at the University of Helsinki. She has worked in education for more than 20 years, from elementary school to the university level. Her most recent research has focused on research ethics and ethics education. She is now studying ways of developing research ethics leadership.

Dr. Erika Löfström is Professor of Education at the University of Helsinki. She is Chair of the non-medical ethics review board at the University of Helsinki, and vice-chair of the Finnish National Board on Research Integrity, and board member of the Academy of Finland. Löfström is involved in two H2020-funded projects on ethics and integrity, namely ENERI European Network of Research Ethics and Research Integrity (2016-2019), and VIRT²UE Virtue based Ethics and Integrity of Research: Train-the-Trainer programme for upholding principles and practices of the European Code of Conduct for Research Integrity (2018-2021). She is currently affiliated with Tallinn University as a visiting professor. 
María Jesús Rodríguez-Triana is Senior Research Fellow at the Centre of Excellence in Educational Innovation of the School of Digital Technologies, Tallinn University. She received her PhD in Information and Communication Technologies from the University of Valladolid (Spain) in 2014, joining the École Polytechnique Fédérale de Lausanne (Switzerland) as a Postdoctoral Fellow. Her research interests have a strong focus on technology-enhanced learning, learning analytics, ethics and data privacy.

Kairi Koort is a lecturer of Systems Biology and acting Head of Curricula in Biology at the School of Natural Sciences and Health at Tallinn University, Estonia. Over the past 20 years, Kairi Koort's research has focused on biomedical studies. She has also been heavily involved in teaching and curricula development in Tartu University, Karolinska Institutet, TalTech and EMBL, during which she developed several undergraduate and graduate Ethics of Science courses for students enrolled in various Natural Sciences Curricula programmes. Currently she is a member of the TLU Sustainability in Higher Education Curricula Committee and the lead co-lecturer for Tallinn University Doctoral Course "The Ethics of Science".

\section{Funding}

This work has been partially funded by the European Union in the context of RID-SSISS (Erasmus + Programme, grand agreement no. 2017-1-ES01-KA203-038303) and CEITER (Horizon 2020 Research and Innovation Programme, grant agreement no. 669074).

\section{Availability of data and materials}

As the current research is based on data collected on a small scale, in one institution and analysed qualitatively, we cannot make the data openly available, as without knowing the context it will be dubious what interpretations can be made based on the data. We cannot dispose institutional context in order to protect the anonymity of the participants. In addition, as some of the data were collected before and some after the new GDP regulations, the informed consent did not specifically ask for the participants' consent to make their data openly available. Nevertheless, we can provide data to other researchers for verification purposes, and we are sharing our aggregated data which shows the overview of each one of the groups in the additional supporting files.

The dataset supporting the conclusions of this article is included within the article.

\section{Competing interests}

The authors declare that they have no competing interests.

Received: 30 May 2019 Accepted: 12 September 2019

\section{Published online: 24 October 2019}

\section{References}

ALLEA (2017) All European academies - the European code of conduct for research integrity (Revised ed.). Brandenburg Academy of Sciences and Humanities, Berlin

Anderson MS, Shaw MA, Steneck NH, Konkle E, Kamata T (2013) Research integrity and misconduct in the academic profession. In: Higher education: handbook of theory and research, pp 217-261

Bebeau MJ, Rest JR, Yamoor CM (1985) Measuring dental students' ethical sensitivity. J Dent Educ 49(4):225-235

Biggs J (1999) What the student does: teaching for enhanced learning. High Educ Res Dev 18(1):57-75

Biggs J, Tang C (2007) Teaching for quality learning at university, 3rd edn. SRHE and Open University Press, Buckingham

Butterfield KD, Trevin LK, \& Weaver GR (2000) Moral awareness in business organizations: Influences of issue-related and social context factors. Human relations, 53(7), 981-1018.

Cavanagh M (2011) Students' experiences of active engagement through cooperative learning activities in lectures. Act Learn High Educ 12(1):23-33

Clarkeburn H (2002) The aims and practice of ethics education in an undergraduate curriculum: reasons for choosing a skills approach. J Furth High Educ 26(4):307-315

Finnish Advisory Board on Research Integrity (2009) Ethical principles of research in the humanities and social and behavioural sciences and proposals for ethical review. http://www.tenk.fi/sites/tenk.fi/files/ethicalprinciples.pdf. Accessed 12 Apr 2019

Fisher CB, Kuther TL (1997) Integrating research ethics into the introductory psychology course curriculum. Teach Psychol 24(3):172-175

Hook P (2011) HookED. http://pamhook.com/solo-taxonomy/. Accessed 20 May 2019

Hyytinen H, Löfström E (2017) Reactively, proactively, implicitly, explicitly? Academics' teaching conceptions of research ethics and integrity. J Acad Ethics 15(1):23-41

Johnson DW, Johnson RT (1999) Making cooperative learning work. Theory Pract 38(2):67-73

Johnson RT, Johnson DW (1986) Cooperative learning in the science classroom. Sci Child 24(2):31-32

Jordan J, Brown ME, Treviño LK \& Finkelstein S (2013) Someone to look up to: Executive-follower ethical reasoning and perceptions of ethical leadership. Journal of management, 39(3), 660-683.

Jordan SR (2013) Conceptual clarification and the task of improving research on academic ethics. J Acad Ethics 11(3):243-256

Kawulich BB (2005) Participant observation as a data collection method. In: Forum qualitative sozialforschung/forum: qualitative social research (Vol. 6, No. 2)

Kim S, Phillips WR, Pinsky L, Brock D, Phillips K, Keary J (2006) A conceptual framework for developing teaching cases: a review and synthesis of the literature across disciplines. Med Educ 40(9):867-876

Kvalnes $\varnothing$ (2014) Leadership and moral neutralisation. Leadership 10(4):456-470

Kvalnes $\varnothing$ (2019) Moral neutralization. In: Moral reasoning at work. Palgrave Pivot, Cham, pp 117-131

Löfström E (2012) Students' ethical awareness and conceptions of research ethics. Ethics Behav 22(5):349-361

Löfström E, Trotman T, Furnari M, Shephard K (2015) Who teaches academic integrity and how do they teach it? High Educ 69(3):435-448 
Morton KR, Worthley JS, Testerman JK, Mahoney ML (2006) Defining features of moral sensitivity and moral motivation: pathways to moral reasoning in medical students. J Moral Educ 35(3):387-406

Myyry L (2003) Components of morality: a professional ethics perspective on moral motivation, moral sensitivity, moral reasoning and related constructs among university students. Doctoral dissertation. University of Helsinki

Niemi P (2016) Six challenges for ethical conduct in science. Sci Eng Ethics 22(4):1007-1025

Rest JR (1986) Moral development: advances in research and theory. Praeger, New York

Rissanen M, Löfström E (2014) Students' research ethics competences and the university as a learning environment. Int J Educ Integr 10(2):17-30

Shephard K, Trotman T, Furnari M, Löfström E (2015) Teaching research integrity in higher education: policy and strategy. J High Educ Policy Manag 37(6):615-632

Slavin RE (1980) Cooperative learning. Rev Educ Res 50(2):315-342

Smith KA, Sheppard SD, Johnson DW, Johnson RT (2005) Pedagogies of engagement: classroom-based practices. J Eng Educ 94(1):87-101

Sparks JR, Hunt SD (1998) Marketing researcher ethical sensitivity: conceptualization, measurement, and exploratory investigation. J Mark 62(2):92-109

Stringer ET (1999) Action research second edition. Sage, Thousand Oaks

Suciu A, Mâtă L (2010) Conceptual delimitations regarding pedagogical competenc(i)e(s). J Plus Educ IV(2):189-200

Teadustava H (2017) Estonian code of conduct for research integrity. Centre for Ethics, University of Tartu, Tartu https:/www. eetika.ee/sites/default/files/www_ut/hea_teadustava_eng_trukis.pdf. Accessed 20 May 2019

Turner SP, Beemsterboer PL (2003) Enhancing academic integrity: formulating effective honor codes. J Dent Educ 67(10): $1122-1129$

Vygotsky L (1978) Interaction between learning and development. Read Dev Child 23(3):34-41

Wood D, Bruner JS, Ross G (1976) The role of tutoring in problem solving. J Child Psychol Psychiatry 17(2):89-100

Zucchero RA (2008) Can psychology ethics effectively be integrated into introductory psychology? J Acad Ethics 6(3):245-257

\section{Publisher's Note}

Springer Nature remains neutral with regard to jurisdictional claims in published maps and institutional affiliations.

- fast, convenient online submission

- thorough peer review by experienced researchers in your field

- rapid publication on acceptance

- support for research data, including large and complex data types

- gold Open Access which fosters wider collaboration and increased citations

- maximum visibility for your research: over $100 \mathrm{M}$ website views per year

At BMC, research is always in progress.

Learn more biomedcentral.com/submissions 